\title{
THE EFFECT OF CEREBROLYSIN ON CISPLATIN-INDUCED OXIDATIVE ACOUSTIC NERVE INJURY IN RATS
}

\author{
ERTUGRUL ERHAN ${ }^{1 *}$, RANA BAYRAM ${ }^{2}$, BAHADIR SULEYMAN ${ }^{3}$, \\ NEZAHAT KURT $^{4}$, HALIS SULEYMAN ${ }^{3}$ and ISMAIL SALCAN ${ }^{2}$ \\ 'Department of Otorhinolaryngology, Faculty of Medicine, \\ Erzincan Binali Yildirim University, Erzincan, Turkey \\ ${ }^{2}$ Department of Otorhinolaryngology \\ Mengucekgazi Education and Research Hospital, Erzincan, Turkey \\ ${ }^{3}$ Department of Pharmacology, Faculty of Medicine, \\ Erzincan Binali YildirimUniversity, Erzincan, Turkey \\ ${ }^{4}$ Department of Biochemistry, Faculty of Medicine, Ataturk University,
} Erzurum, Turkey

\begin{abstract}
One of the major side effects of dose-limiting cisplatin is ototoxicity, resulting in restricted clinical use. Cerebrolysin is a neuroprotective, neurotrophic and antioxidant drug derived from the brains of pigs. No studies have investigated the positive effects of Cerebrolysin on the damage to auditory nerves caused by cisplatin-induced oxidative stress. Eighteen rats were randomly divided into three groups of six: the Cerebrolysin and cisplatin group (CCG), the cisplatin group (CG) and the healthy group (HG). The CCG was administered $2.5 \mathrm{~mL} / \mathrm{kg}$ of Cerebrolysin via subcutaneous injection daily, while the CG and HG were administered physiological saline solutions daily. Every other day, after receiving their dose of Cerebrolysin or physiological saline solution, the CCG and CG groups were administered $5 \mathrm{mg} / \mathrm{kg}$ of cisplatin via intraperitoneal injection (IP) every other day. The substances were administered for eight days. In acoustic nerve tissue, while the CC's oxidant parameters were significantly higher $(\mathrm{p}<0.0001)$ than those of the CCG and HG groups, its antioxidant parameters were also significantly lower $(\mathrm{p}<0.0001)$. Cerebrolysin antagonized the balance of oxidants and antioxidants in acoustic nerve tissue, resulting in higher concentrations of oxidants. The results suggested that Cerebrolysin may be useful in the treatment of cisplatin-induced oxidative acoustic nerve injury.
\end{abstract}

Keywords: Cerebrolysin, acoustic nerve, cisplatin, rats

Cisplatin (cis-diamminedichloroplatinum II) is a strong anticarcinogenic drug used to treat several types of cancer; however, it has severe adverse effects $(1,2)$. For example, Bayram et al.'s experimental data demonstrated the ototoxic effects of cisplatin (3). In literature addressing neurotoxicity, auditory nerve damage has been reported as one of the most severe adverse effects of cisplatin (2). Feghali et al. reported that cisplatin injured auditory neurons and hair cells (4). In addition, dose-limiting cisplatin can result in major adverse effects, specifically ototoxicity (5). Similar to reactive oxygen species (ROS), cisplatin is able to generate toxic oxygen species and inhibit antioxidant systems (6). ROS compounds also possess unpaired electrons, such as hydroxyl, superoxide, lipid peroxide, and divalent metals, and are toxic to auditory neurons (7). Cisplatin has been reported to elevate lipid peroxidation (LPO) and malondialdehyde (MDA) production in the internal ear and suppress total glutathione (tGSH) generation (8). These findings indicate that cisplatin causes ototoxicity by promoting oxidative stress.

In this study, we analyzed Cerebrolysin's ability to protect the auditory nerves from oxidative damage caused by cisplatin. Cerebrolysin is a drug consisting of amino acids and peptides with low molecular weights; it is a neuroprotective and neurotrophic drug with antioxidant properties and is derived from the brains of pigs. Moreover, recent

\footnotetext{
* Corresponding author: e-mail: dreerhan@hotmail.com
} 
studies have confirmed the antioxidant properties of Cerebrolysin (9). In addition, other studies have also reported that it inhibits apoptosis induced by oxidative stress (10) and stabilizes the acute stressinduced elevation of LPO (11). While these findings suggest that Cerebrolysin may protect auditory nerve tissue against cisplatin-induced oxidative damage, no research has explored or confirmed it. Therefore, in this study, we evaluated Cerebrolysin's ability to protect the auditory nerves from cisplatin-induced oxidative damage in rats using biochemical and histopathological analysis.

\section{MATERIAL AND METHOD}

\section{Animals}

In our research, we used 18 male albino Wistar rats, with body weights varying from 298 to $310 \mathrm{~g}$, supplied by Ataturk University's Medical Experimental Research and Application Center. The rats were fed and kept at an ambient temperature of $22^{\circ} \mathrm{C}$ before conducting the experiment. The protocols and procedures used in this experiment were approved by Atatürk University's Animal Experimentation Ethics Committee with Letter No: $13 / 244$, dated 27/12/2018.

\section{Chemical substances}

CDDP (50 mg/100 mL; Cisplatin Ebewe), thiopental sodium and Cerebrolysin were provided by Liba (Turkey), I.E. Ulagay (Turkey) and EVER Pharma (Austria), respectively.

\section{Experimental groups}

The rats were randomly divided into three groups of six: the Cerebrolysin and cisplatin group (CCG), the cisplatin group (CG) and the healthy group (HG).

\section{Experimental procedure}

Rats in the CCG were administered $2.5 \mathrm{~mL} / \mathrm{kg}$ of Cerebrolysin via subcutaneous injection daily, Rats in CG and HG were administered $1 \mathrm{~mL}$ of physiological saline solution daily by oral gavage. Every other day, one hour after receiving a dose of Cerebrolysin or physiological saline solution, rats in the CCG and CG were administered $5 \mathrm{mg} / \mathrm{kg}$ of cisplatin via intraperitoneal (IP) injection. The substances were administered for eight days, and then the rats were sacrificed using a high-dose anesthetic agent. Their acoustic nerve tissues were extracted and the malondialdehyde (MDA), total glutathione (tGSH), total oxidant (TOS), and total antioxidant (TAS) capacity levels were determined. The nerve tissues also underwent histopathological analysis. CCG results were then compared to CG and HG results.

\section{Biochemical analyses \\ Malondialdehyde assessment}

Ohkawa et al.'s method, which was based on the optical density measurement of the color MDA developed when reacting with thiobarbituric acid in hot and acidic contexts at $532 \mathrm{~nm}$, was used to assess MDA (12). Specifically, 25 of sodium dodecyl sulphate $(80 \mathrm{~g} / \mathrm{L})$ and $1 \mathrm{~mL}$ mix $(200 \mathrm{~g} / \mathrm{L}$ acetic acid $+1.5 \mathrm{~mL} 8 \mathrm{~g} / \mathrm{L}$ 2-thiobarbituric acid) were added to a 25 sample. The mixture was then heated at $95^{\circ} \mathrm{C}$ for $60 \mathrm{~min}$. When cooled, it was centrifuged at $4000 \mathrm{rpm}$ for $10 \mathrm{~min}$. The upper layer's absorption coefficient was measured at $532 \mathrm{~nm}$. The concentration of MDA in the sample was determined using a calibration curve plotted with 1,1,3,3tetraethoxypropane.

\section{Total glutathione assessment}

According to Sedlak et al.'s method, 5,5'dithio-bis-(2-nitrobenzoic) acid (DTNB) disulfide is chromogenic in the medium and is reduced easily by sulphydryl groups (13). The yellow color produced during the reduction was measured using spectrophotometry at $412 \mathrm{~nm}$. For measurement, a cocktail solution comprising $5.85 \mathrm{~mL}$ of $0.1 \mathrm{M}$ sodium phosphate buffer, $2.8 \mathrm{~mL}$ of $0.001 \mathrm{M}$ DTNB, 3.75 $\mathrm{mL}$ of $0.001 \mathrm{M} \mathrm{NADPH}$, and $80 \mu \mathrm{L}$ of $625 \mathrm{U} / \mathrm{L}$ glutathione reductase was prepared. Before measurement, $0.1 \mathrm{~mL}$ of meta-phosphoric acid was added to $0.1 \mathrm{~mL}$ of tissue homogenate and centrifuged for $2 \mathrm{~min}$ at $2000 \mathrm{rpm}$ for deproteinization. Then, 0.15 $\mathrm{mL}$ of the cocktail solution was added to $50 \mu \mathrm{L}$ of supernatant. The standard curve was obtained using GSSG.

Total oxidant and total antioxidant capacity assessment

The TOS and TAS levels of tissue homogenates were determined using a novel automated measurement method and commercially available kits (Rel Assay Diagnostics, Turkey), both of which were recommended in Erel's publications $(14,15)$. His method of measuring TAS capacity was based on bleaching the characteristic color of a more stable 2,2'-azino-bis-(3-ethylbenzothiazoline6-sulfonic) acid radical cation using antioxidants and performing measurements at $660 \mathrm{~nm}$. The results were expressed in $\mu \mathrm{mol}$ of hydrogen peroxide $\left(\mathrm{H}_{2} \mathrm{O}_{2}\right)$ equivalent per gram of protein. In his TOS method, the oxidants present in the sample oxi- 
dized the ferrous ion-o-dianisidine complex to ferric ions. This reaction was enhanced by glycerol molecules, which were abundant in the reaction medium. The ferric ions produced a colored complex with xylenol orange in an acidic medium. The color intensity, which could be measured at $530 \mathrm{~nm}$ via spectrophotometry, was related to the oxidant concentration in the sample. The results were expressed as $\mu \mathrm{mol}$ of Trolox equivalent per gram of protein.

\section{Statistical analyses}

The results obtained from the experiments were expressed as mean \pm standard deviation (SD). One-way ANOVA was used to determine statistically significant differences between groups. Fisher's least significant difference (LSD) test was performed afterward. All statistical procedures were performed in SPSS Statistics v20, and $\mathrm{p}<0.05$ was considered statistically significant.
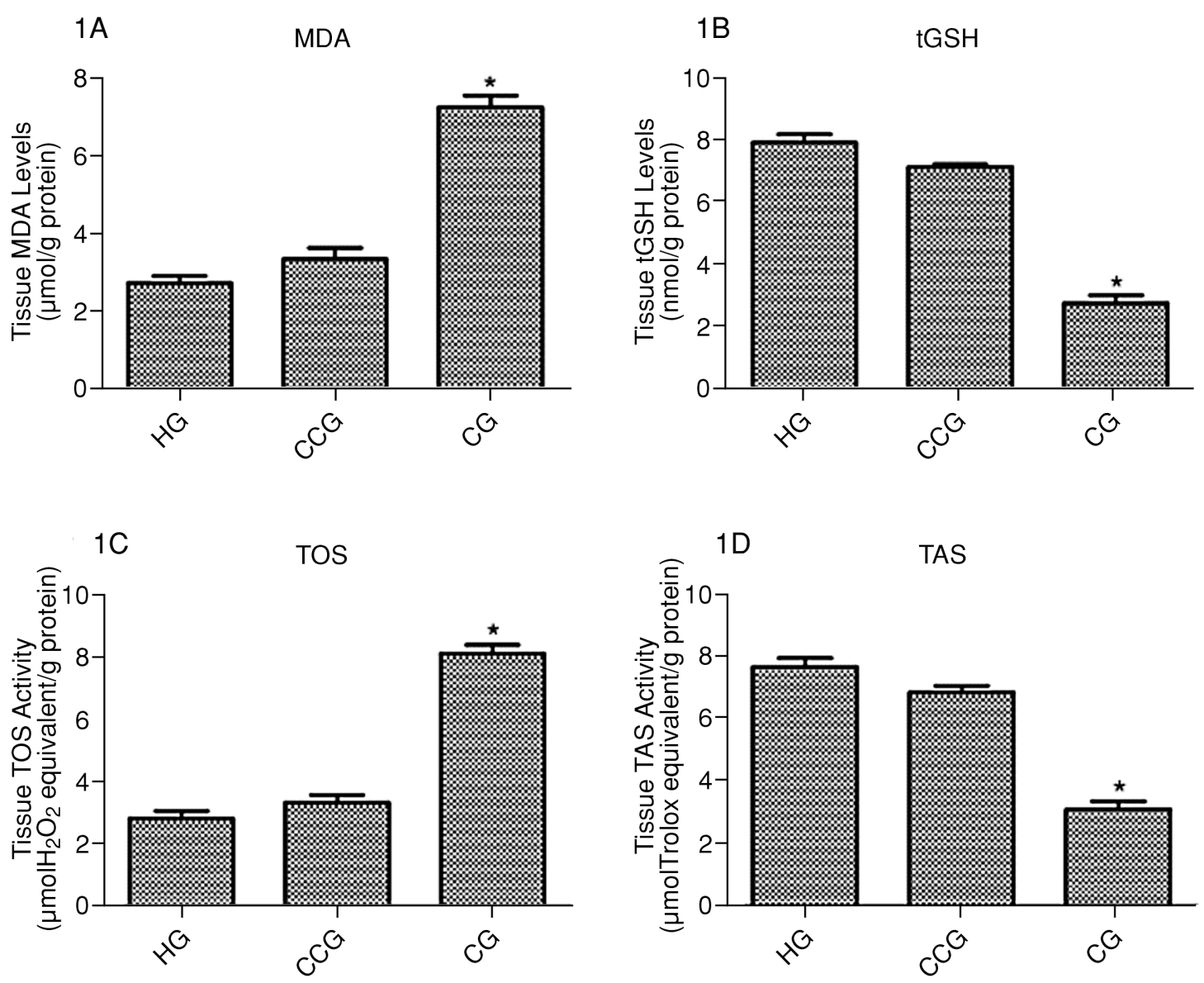

Figure 1. The oxidant and antioxidant levels in the acoustic nerve tissues of each group. 1A: MDA levels 1B: tGSH levels 1C: TOS levels 1D: TAS levels.

${ }^{*} \mathrm{p}<0.0001$, according to the HG. 
In this study, biochemical analyses were performed to determine the effect of Cerebrolysin on oxidative acoustic nerve injury developed by the administration of cisplatin in rats. Our biochemical experimental findings revealed that MDA concentrations in acoustic nerve tissue were elevated in the CG compared to the CCG and HG. MDA is the most well-known aldehyde among those occurring as a result of LPO; it causes the polymerization of membrane components, leading to severe cellular damage (16). LPO reactions are either ended by scavenger antioxidant reactions or continued by autocatalytic diffusion reactions (17). The literature suggests that Cerebrolysin might inhibit LPO in scavenger antioxidant reactions. In addition, ROS, endogenous GSH, glutathione peroxidase (GPO), glutathione reductase (GRx), glutathione-transferase (GST), superoxide dismutase (SOD), catalase (CAT), and other antioxidants (vitamins A, C and E) are neutralized by defense systems (18). Cerebrolysin's ability to reduce elevated MDA concentrations caused by cisplatin in the acoustic nerve tissue suggests that it is a broad-spectrum antioxidant. Cisplatin also elevates ROS production, leading to nerve damage caused by oxidation. ROS are peroxynitrites consisting of superoxide anions $\left(\mathrm{O}_{2} \cdot^{-}\right)$, hydroxyl radicals $(\bullet \mathrm{OH})$, hydrogen peroxide $\left(\mathrm{H}_{2} \mathrm{O}_{2}\right)$, hypochloric acid, and nitric oxide (19).

The TOS levels were measured to determine if all ROS were suppressed by Cerebrolysin. As there were several oxidant molecules requiring complicated techniques, all ROS were subjected to TOS analysis (15). Oxidative stress has been found to play a role in the pathogenesis of auditory neuron damage caused by cisplatin $(4,8)$. Furthermore, several studies have reported on the association between cisplatin's ototoxicity pathogenesis and TOS and TAS levels (20). However, the literature review revealed that no studies have explored the effects of Cerebrolysin on acoustic nerve damage caused by cisplatin-induced oxidative stress. On the other hand, some studies report that Cerebrolysin inhibited nitrogen monoxide development and LPO final products in chemical, fermentative and cellular model systems $\left(\mathrm{O}_{2} \cdot^{-}\right)$. (21). In addition, other studies associate the neuroprotective and neurotrophic effects of Cerebrolysin with antioxidant activity. Abdel-Salam et al. reported that Cerebrolysin prevented neural loss by inhibiting ROS development and LPO (22). Cheran et al. used an experimental method to show the protective effect of Cerebrolysin on acoustic nerve cells (23). Our findings and literature data show that Cerebrolysin effectively inhibits acoustic nerve damage caused by cisplatin-induced oxidative stress.
In this study, Cerebrolysin was found to inhibit the reduction of tGSH levels in acoustic nerve tissue caused by cisplatin. GSH is a tripeptide endogenous antioxidant molecule consisting of L-glutamate, L-cysteine and glycine; it has antioxidant features when it reacts with $\mathrm{H}_{2} \mathrm{O}_{2}$, organic peroxides and $\mathrm{H}_{2} \mathrm{O}_{2}$ discharge from cells. GSH chemically detoxifies hydrogen peroxide and organic oxides and protects cells from ROS damage (24). However, reduced tGSH levels in the $\mathrm{CP}$ suggest that tGSH insufficiently detoxifies ROS associated with cisplatin. In the literature, an antioxidant's inability to neutralize oxidants is defined as oxidative stress (25). Our experimental findings revealed that Cerebrolysin antagonized and suppressed the oxidant-antioxidant ratio changes caused by cisplatin. The literature also defines shifts in oxidant-antioxidant balance towards oxidants as oxidative stress (26). In our study, we analyzed Cerebrolysin's influence on TAS levels to reveal its broad-spectrum antioxidant effects. Our findings revealed that the CCG's TAS levels were significantly higher than those in the $\mathrm{CG}$, proving that Cerebrolysin has broad-spectrum antioxidant activity. Both our experimental findings and literature data show that Cerebrolysin displayed enzymatic and non-enzymatic antioxidant activity, specifically for GSH, GPO, GRx, GST, SOD, and CAT concurrently. Moreover, GSH discharges $\mathrm{H}_{2} \mathrm{O}_{2}$ from cells when it reacts with $\mathrm{H}_{2} \mathrm{O}_{2}$ and organic peroxides when catalyzing GPO. Further, GPO protects lipids from oxidation at an intracellular level, while GRx transforms oxidized glutathione into reduced glutathione. GSTs bond foreign substances with cysteine's -SH group in glutathione and, thus, neutralizes their electrophilic regions. SOD catalyzes superoxide's dismutation reaction, and CAT inhibits hydrogen peroxide accumulation at the end of the reaction, which is catalyzed with SOD (25).

\section{CONCLUSIONS}

In conclusion, cisplatin influenced the oxidant-antioxidant balance, pushing it in favor of oxidants in the acoustic nerve tissue of rats. Cerebrolysin neutralized this adverse effect by rebalancing the ratio of oxidants and antioxidants. Our experimental findings suggest that Cerebrolysin may be useful in the treatment of acoustic nerve damage caused by cisplatin-induced oxidative stress.

\section{Conflict of interest}

The authors declare no conflict of interest. 


\section{REFERENCES}

1. Sakamoto M., Kaga K., Kamio T.: Otolaryngol. Head Neck Surg. 122, 828 (2000).

2. Gabaizadeh R., Staecker H., Liu W., Kopke R., Malgrange B., et al.: Acta Otolaryngol. 117, 232 (1997).

3. Bayram A., Kaya A., Akay E.,'Hira I., Ozcan I.: Int. J. Pediatr. Otorhinolaryngol. 94, 1. (2017).

4. Feghali J.G., Liu W., Van De Water T.R.: Laryngoscope 111, 1147 (2001).

5. Cooley M.E., Davis L., Abrahm J.: Cancer Nurs. 17, 283 (1994).

6. Fetoni A.R., Sergi B., Ferraresi A., Paludetti G., Troiani D.: Acta Otolaryngol. 124, 421 (2004).

7. Freeman B.A., Capo J.D.: Lab. Invest. 47, 412 (1982).

8. Kuduban O., Kucur C., Sener E., Suleyman H., Akcay F.: Scientific World Journal 2013, 5 pages (2013).

9. Berent D., Zboralski K., Macander M.: Pol. J. Aviat. Med. Psychol. 20, 25 (2014).

10. Boshra V., Atwa A.: Physiol. Int. 103, 310 (2016).

11. Deviatkina T.A., Vazhnichaia E.M., Lytsenko R.V.: Eksp. Klin. Farmakol. 63, 38 (2000).

12. Ohkawa H., Ohishi N., Yagi K.: Anal. Biochem. 95, 351 (1979).

13. Sedlak J., Lindsay R.H.: Anal. Biochem. 25, 192 (1968).
14. Erel O.A.: Clin. Biochem. 37, 112 (2004).

15. Erel O.: Clin. Biochem. 38, 1103 (2005).

16. Goulart M., Batoreu M.C., Rodrigues A.S., Laires A., Rueff J.: Mutagenesis 20, 311 (2005).

17. Gutteridge J.M.C.: Clin. Chem. 41, 1819 (1995).

18. Urso M.L., Clarkson P.M.: Toxicology 189, 41 (2003).

19. Toyokuni S.: Pathol. Int. 49, 91 (1999).

20. Kara M., Türkön H., Karaca T., Güçlü O., Uysal S., et al.: Int. J. Pediatr. Otorhinolaryngol. 85, 12 (2016).

21. Gaitetdinova D.D., Semenov V.V., Ismagilov M.F., Kharitonov V.S.: Eksp. Klin. Farmakol. 69, 58 (2006).

22. Abdel-Salam O.M.E., Mohammed N.A., Youness E.R., Khadrawy Y.A., Omara E.A., Sleem A.A.: J. Neurorestoratol. 2, 47 (2014).

23. Cheran L.E., Cheung S., Al Chawaf A., Ellis J.S., Belsham D.D., et al.: Analyst 132, 242 (2007).

24. Murray RK, Granner DK, Mayes PA, VM. R.: Harper's Biochem, 25 th Edition, McGraw-Hill Press, USA 2000.

25. Suleyman H., Gül V., Erhan E.: Erzincan Med. J. 1, 1 (2018).

26. Yeum K-J, Russell M.R., Krinsky I.N., Adlini G.: Arch. Biochem. Biophys. 430, 97 (2004).

(C) 2020 by Polish Pharmaceutical Society. This is an access article under the CC BY NC license (c) (i) () (http://creativecommons.org/licenses/by-nc/4.0/). 